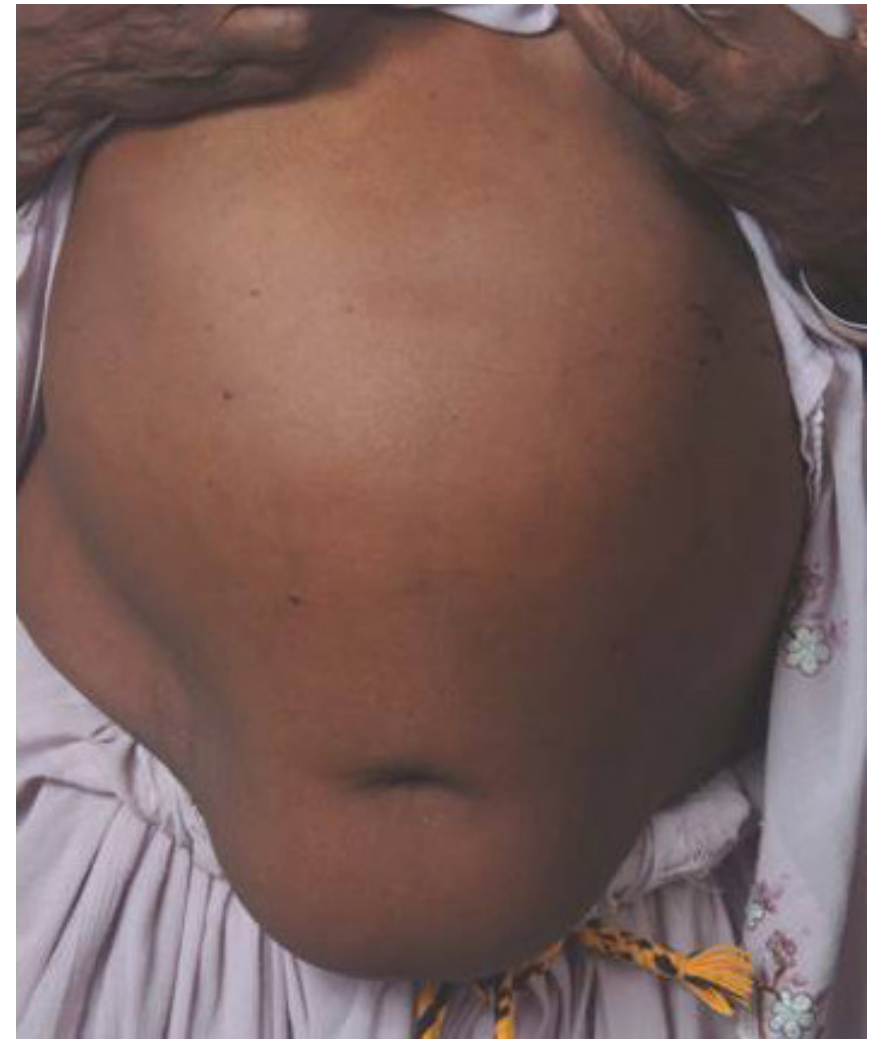

Figure 1: Photograph of the patient showing a large abdominal lump due to giant hydatid cyst of the liver.

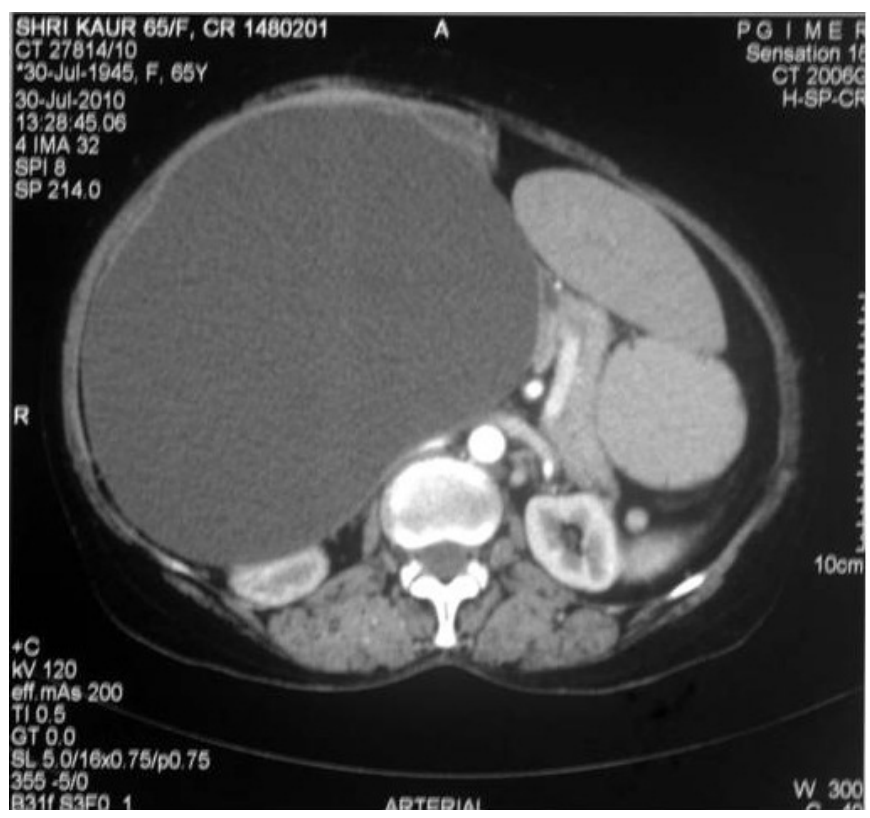

Figure 2: Contrast-enhanced CT scan of the abdomen showing a $19 \mathrm{~cm} \times 15 \mathrm{~cm} \times 12.5 \mathrm{~cm}$ cystic mass in the V, VI and VII segment of the right lobe of the liver, extending into the hepatorenal fossa and compressing the right kidney.

Echinococcus granulosus. Surgery was performed for deroofing of the cyst combined with omentopexy.

SACHIN GUPTA ${ }^{1}$, SUNIL TANEJA ${ }^{1}$,
AJAY DUSEJA ${ }^{1}$, RK DHIMAN ${ }^{1}$,

YOGESH CHAWLA ${ }^{1}$, NAVEEN KALRA ${ }^{2}$, ARUNANSHU BEHERA ${ }^{3}$

Correspondence: Dr. Ajay Duseja ${ }^{l}$ Department of Hepatology ${ }^{1}$, Radiodiagnosis ${ }^{2}$ and

General Surgery ${ }^{3}$, Post Graduate Institute of Medical Education and Research Sector-12, Chandigarh, India Email:ajayduseja@yahoo.co.in

\section{An unusual presentation of Castleman's disease}

\section{Introduction}

Castleman's disease is a rare lymphoproliferative condition of unknown origin, which was first described in $1954 .{ }^{1}$ In the majority of reported cases, the disorder is located in the mediastinum, whereas mesenteric involvement is very unusual. ${ }^{2}$ Clinically, it may present as unicentric or multicentric disease and histologically it is classified as hyaline vascular, plasmacell and mixed-cellular type. The hyaline vascular type is found most commonly in unicentric disease and plasma-cell type in multicentric disease. We describe a case of plasma-cell variant mesenteric Castleman's disease which presented as a mass in the abdomen.

\section{Case report}

A 30-year-old man presented with pain of 4 months duration in the left upper part of the abdomen. The patient also noticed a lump in the abdomen 2 months before presentation. Examination of the abdomen showed a firm, smooth lump in the left lumbar region, $4 \mathrm{~cm} \times 4 \mathrm{~cm}$ in size. It was non-tender and mobile in all directions. Mild splenomegaly was also present. Investigations showed the presence of anaemia (haemoglobin $8.2 \mathrm{~g} / \mathrm{dL}$ ) of normocytic and normochromic RBCs without any evidence of atypical cells and an ESR of $40 \mathrm{~mm}$. Contrastenhanced computed tomography (CECT) scan of the abdomen and the thorax showed a well-defined mass $6 \mathrm{~cm} \times 6 \mathrm{~cm}$ in size arising from the mesentery on the left side with mild hepatosplenomegaly. Fibrotic lesions were present in the upper lobes of both the lungs with no mediastinal lymph node 
enlargement. Fine-needle aspiration cytology (FNAC) from the abdominal mass showed lymphoid hyperplasia. An exploratory laparotomy revealed a mesenteric mass of size $8 \mathrm{~cm} \times 6 \mathrm{~cm}$. Excision of the mass was performed and sent for histopathological examination. Many hyperplastic follicles were seen, surrounded by a concentric arrangement of lymphocytes with mantle-zone expansion. Numerous plasma cells and Russell bodies were seen, suggestive of unicentric Castleman's disease of plasma-cell type (Figure $1 \&$ 2). The biopsy specimen was negative for human herpes virus (HHV)-8 DNA by polymerase chain reaction (PCR). The patient was followed up for approximately 12 months after curative resection. There has been no recurrence of abdominal lump and no evidence of any active disease.

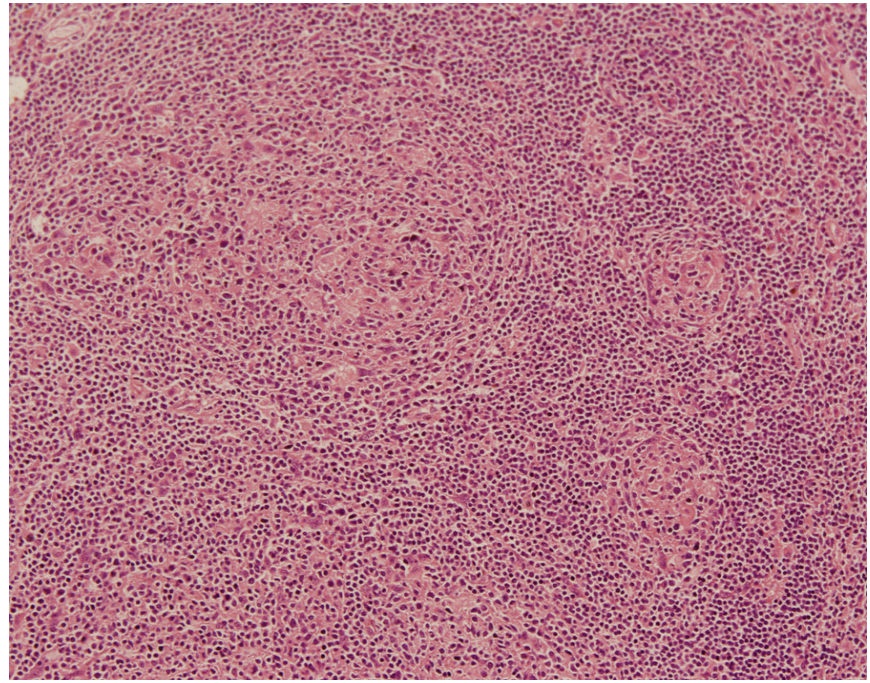

Figure 1: $\quad$ 10X (H\&E) Multiple varying sizes germinal centre-like areas with arrangement of mature lymphocytes in a necklace-like fashion

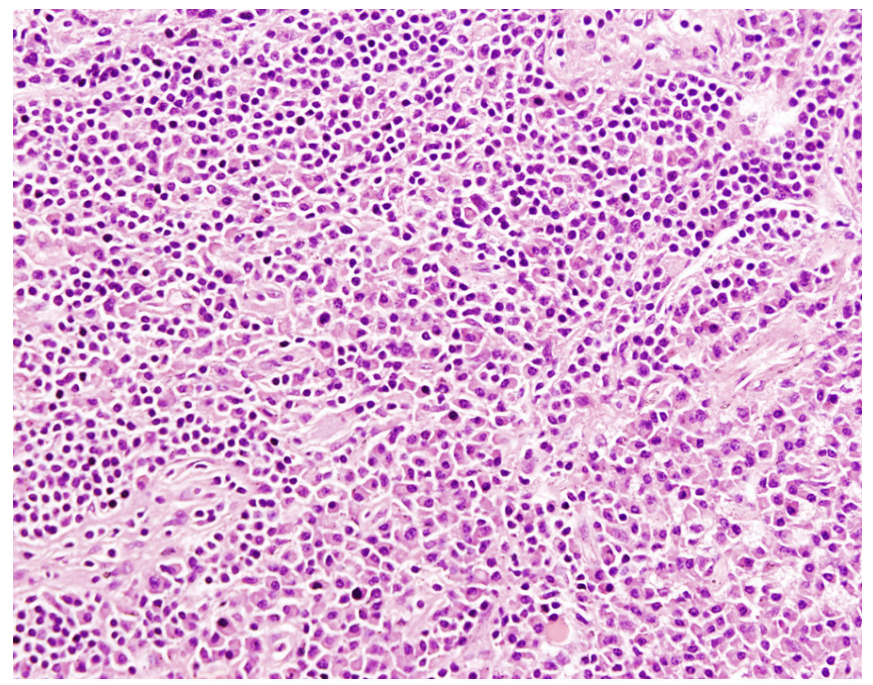

Figure 2: 40X Inter-germinal centre-like areas are infiltrated by sheets of mature plasma cells with presence of Russell bodies

\section{Discussion}

Castleman's disease is a rare lymphoproliferative disorder with a varied clinical presentation. The disease has been classified as unicentric or multicentric.,4 The unicentric type usually has a benign course presenting as a solitary mass without much constitutional symptoms except for abdominal or chest mass. The multicentric type presents with widespread lymphadenopathy, raised IL-6 levels and is usually associated with HHV-8. ${ }^{5}$ The exact mechanisms causing this condition are poorly understood. Immune dysregulation through immunosuppression, autoimmune processes or continuous low-grade inflammation is a key factor. ${ }^{4,6}$ IL-6 elevation is associated with both unicentric and multicentric forms. ${ }^{7}$ It stimulates B-cell proliferation, leading to hyperplastic follicles and hence enlarged lymph nodes. It also promotes the secretion of vascular endothelial growth factor (VEGF), activating angiogenesis and promoting hypervascularity. It activates acute phase reactants leading to raised ESR and raised levels of C-reactive protein (CRP), immunoglobulins, fibrinogen and serum-associated amyloid (SAA). ${ }^{7}$ Histologically, two major types of Castleman's disease have been described-hyaline vascular type and plasma-cell type. The hyaline vascular variety, being the most common variant found in younger patients, is usually benign, with a self-limiting clinical course. ${ }^{3}$ The hyaline vascular form has a poorly formed germinal centre surrounded by an expanded mantle zone, having rims of CD-20 positive mature lymphocytes arranged concentrically in an “onion-skin" or whorled appearance. ${ }^{2}$

The plasma-cell variant of Castleman's disease is usually multicentric with a grave prognosis and a risk of lymphomatous transformation in future. But rarely, it may present as an unicentric variant with a good prognosis, and responds to curative resection as observed in this patient. Despite tuberculosis being endemic in India, a clinical picture involving lymphadenopathy, abdominal mass and weight loss may not always be diagnosed as abdominal tuberculosis. A far-fetched diagnosis such as Castleman's disease may also have to be kept in mind.

\section{HEMANTA KUMAR NAYAK, UJJWAL SONIKA, VANGIPURAM DEEPAK RAJKUMAR, PREMASHISKAR, \\ R.K. SARAN, SURESHKUMAR, NARESH KUMAR,}


Correspondence: Dr Hemanta Kumar Nayak, Department of Medicine, LN Hospital, Maulana Azad Medical

College, New Delhi, India.

Emaildrhemantnayak@gmail.com

\section{References}

1. Castleman B, Towne VW. CASE records of the Massachusetts General Hospital Weekly Clinicopathological Exercises: Case 40011. N Engl J Med. 1954;250:26-30.

2. Kimura T, Inoue T, Katayama K, Hirose K, Imamura Y, Yamaguchi A. Mesenteric Castleman's disease: report of a case. Surg Today. 2002;32:651-4.

3. Rosai J. Rosai and Ackerman's surgical pathology. 9th ed. New Delhi: Elsevier; 2004:1905-8.

4. Francis ND, Hollowood K, Gabriel R. Angiofollicular lymph node hyperplasia. J Clin Pathol. 1988;41:353-4.

5. Cesarman E, Knowles DM. Kaposi's sarcoma-associated herpesvirus: a lymphotropic human herpesvirus associated with Kaposi's sarcoma, primary effusion lymphoma, and multicentric Castleman's disease. Semin Diagn Pathol. 1997;14:54-66.

6. Frizzera G. Castleman's diesease: more questions than answers. Hum Pathol. 1985;156:202-5.

7. Yoshizaki K, Matsuda T, Nishimoto N, Kuritani T, Taeho L, Aozasa K, et al. Pathogenic significance of interleukin-6 (IL-6/ BSF-2) in Castleman's disease. Blood. 1989;74:1360-7. unremarkable except for multiple cutaneous neurofibromas, axillary freckles and cafe au lait spots (Figure 1). Haematological tests revealed microcytic hypochromic anaemia and faecal occult blood was positive. Both upper GI endoscopy (UGIE) and colonoscopy were normal. CT angiogram of the abdomen (Figure 2) revealed the presence of two masses $3 \mathrm{~cm}$ $\times 2 \mathrm{~cm}$ in size, enhancing well with contrast, located in the proximal and mid jejunum and supplied by branches of the superior mesenteric artery. After obtaining an informed consent and preoperative packed cell transfusions, the patient was taken up for diagnostic laparoscopy. Findings at laparoscopy included two jejunal tumours as described above and additional

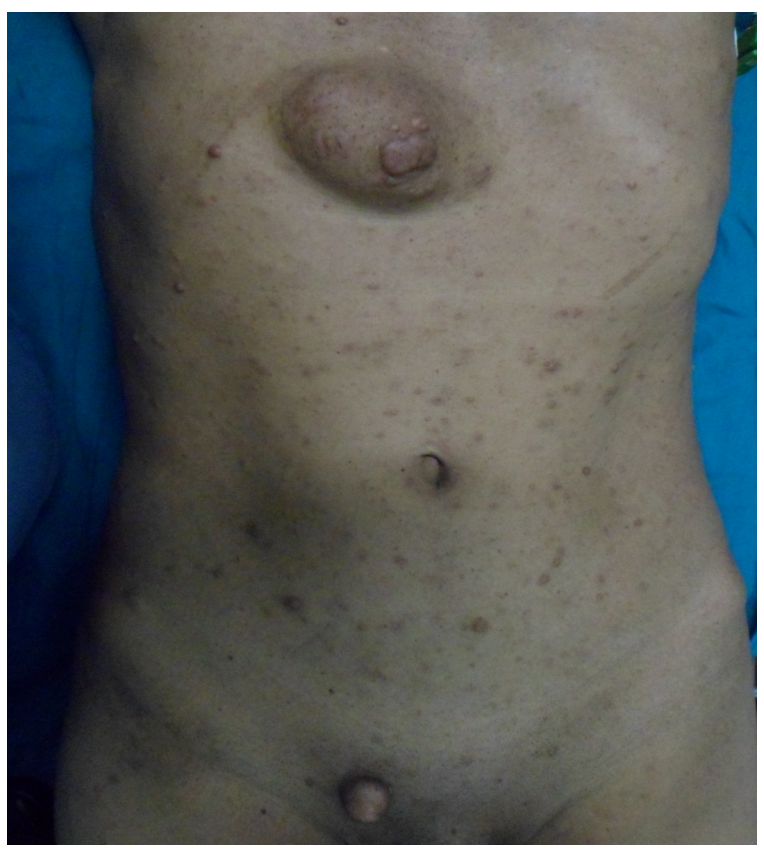

Figure 1: Multiple neurofibromas distributed over the patient's body

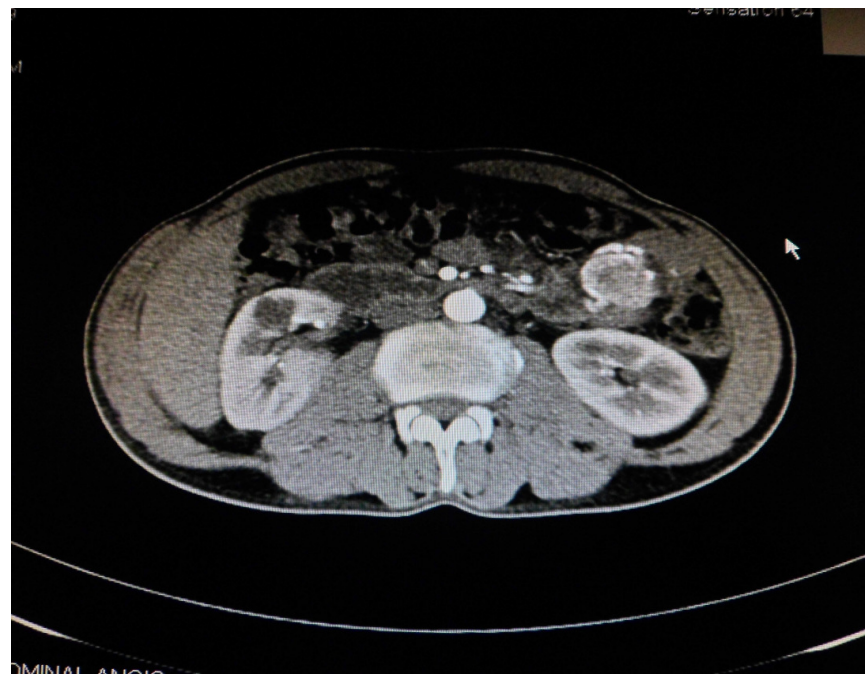

Figure 2: Axial contrast-enhanced CT (CECT) scan showing a wellenhancing lesion $3 \mathrm{~cm} \times 2 \mathrm{~cm}$ in size, arising from the proximal jejunum of 2 weeks' duration. The patient denied history of ingestion of alcohol or medications. Clinical examination was
Patients with neurofibromatosis type 1 (Von Recklinghausen's disease, NF 1) suffer from cutaneous, neurological and intestinal manifestations due to the mutation of the neurofibromin gene and the abnormal protein product. Patients with NF 1 are prone to developing gastrointestinal stromal tumours (GIST). We report the case of successful laparoscopic-assisted small bowel resection of multiple small bowel GISTs in a patient with NF 1.

\section{Case report}

A 42-year-old man presented with recurrent episodes of melaena of alcohol or medications. Clinical examination was 